This manuscript has been submitted for publication in "International Journal of Remote Sensing". Subsequent versions of this manuscript, after acceptance and review by the journal, may have slightly different content. If accepted, the final version of this manuscript will be available via the 'Peer-reviewed Publication DOI'

\title{
Analysing the uncertainty of the CORINE Land Cover time series (1990-2018) for Spain
}

\author{
David García Álvarez ${ }^{1}$ and María Teresa Camacho Olmedo ${ }^{2}$ \\ ${ }^{1}$ Departamento de Geología, Geografía y Medio Ambiente. Universidad de Alcalá. david.garcia@uah.es \\ ${ }^{2}$ Departamento de Análisis Geográfico Regional. Universidad de Granada.
}

CORINE Land Cover is one of the most relevant Land Use Cover (LUC) databases in Europe because of its degree of detail and long time series. Although some studies have assessed the uncertainty of the database for specific years and periods, no work has been found that analyses all the available CORINE time series (1990-2018). In this study, we analyze the uncertainties of the CORINE time series for a specific Spanish region (Asturias). To this end, we compare and analyze the CORINE status layers (CLC) and the CORINE layers of changes (CHA) for each of the mapped periods: 1990-2000, 2000-2006, 2006-2012, $2012-$ 2018. Results show how CLC and CHA layers provide different information, especially after the change of production of CORINE Spain in 2012. The last two CORINE editions (2012, 2018) show a lot of technical changes that make the use of CLC layers very uncertain. In addition, mixed categories, whose definition is imprecise and, therefore, more uncertain, are behind most of detected change in both types of CORINE layers (CHA, CLC).

Keywords: Land use; Land Cover; CORINE Land Cover; Uncertainty; Time series

\section{Introduction}

Land Use and Land Cover (LUC) information is of uttermost importance for many studies in different fields, from social to natural sciences (Green, Schweik and Randolph, 2005; Bontemps et al., 2012). Researchers from these fields demand accurate LUC data at different levels of spatial and thematic detail that are able to characterize regional, national and continental areas, or even the global surface (Giri, 2016; Nedd et al., 2021; García-Álvarez et al., 2022). 
This manuscript has been submitted for publication in "International Journal of Remote Sensing". Subsequent versions of this manuscript, after acceptance and review by the journal, may have slightly different content. If accepted, the final version of this manuscript will be available via the 'Peer-reviewed Publication DOI'

The CORINE Land Cover project, hereinafter CORINE, can be considered the most relevant European LUC database because of its history (the project dates back to 1985), comprehensive coverage (up to 38 countries in the last update), method of production (photointerpretation or data generalization) and degree of detail (Minimum Mapping Unit of 25ha and 5ha for changes) (Falt'an et al., 2020; García-Álvarez and Florina Nanu, 2022). Although new, more detailed and accurate LUC products have been recently generated as part of the Copernicus Land Monitoring Service, such as the High Resolution Layers (HRL) or the Urban Atlas, CORINE remains as a valuable and unique source of LUC information because of its rich time series (García-Álvarez and Florina Nanu, 2022). Despite of its utility and wide use, there are few studies analyzing the CORINE database, its uncertainties and limitations, especially when focusing not only on a single date, but on the whole CORINE time series.

Some of the available analyses on the accuracy and uncertainties of CORINE have been carried out by the national teams in charge of producing the dataset and take part of the validation exercises of the CORINE production's workflow (Torma and Harma, 2004; Caetano, Mata and Freire, 2006; Aune-Lundberg and Strand, 2010, 2021). Other studies have been promoted by the European Environment Agency (EEA) as part of the works developed in the context of the CORINE Land Cover project (European Environment Agency, 2006). In other cases, CORINE has been analyzed together with other global and continental LUC datasets, comparing their agreements and disagreements (Bach et al., 2006; Neumann et al., 2007; Perez-Hoyos, GarciaHaro and Valcárcel, 2014). For specific countries and areas, there are also academic analysis of the CORINE database. Śleszyński et al. (2020) analyze the uncertainty of CORINE built-up areas for Poland. Teixeira et al. (2016) analyze the potential uncertainties of CLC changes for a specific Portuguese area in the period 1990-2006. Fonte et al. (2020) assessed the uncertainty of the 
This manuscript has been submitted for publication in "International Journal of Remote Sensing". Subsequent versions of this manuscript, after acceptance and review by the journal, may have slightly different content. If accepted, the final version of this manuscript will be available via the 'Peer-reviewed Publication DOI'

CORINE classification for a Portuguese city (Coimbra). Ovejero-Campos et al. (2019) have focused on the analysis on CORINE uncertainties for the Spanish-Portuguese coastal border. For Spain, Felicísimo and Sánchez Gago (2002), Catalá Mateo et al. (2008), Barreira González et al. (2012) and Diaz-Pacheco and Gutiérrez (2013) have assessed the CORINE uncertainties for specific areas and covers. García-Álvarez and Camacho Olmedo (2017) and, later, MartínezFernández et al. (2019), have also assessed the consequences of the methodological change in the production of the Spanish CORINE for 2012.

Most of those studies have focused on the analysis of specific editions of CORINE, either to evaluate the general accuracy of the dataset for the area or categories of analysis (Mañas, Soria and Ramírez, 2003; Śleszyński, Gibas and Sudra, 2020), to make a fine scale profile of the CORINE classes (Gallego, 2001; Fonte et al., 2020) or to check the consistency of CORINE with other LUC datasets (Felicísimo and Sánchez Gago, 2002; Neumann et al., 2007; Perez-Hoyos, Garcia-Haro and Valcárcel, 2014). The analysis of the LUC changes showed by CORINE is usually lacking and, when existing, it usually limits to a couple of dates, without exploring the full CORINE time series (Catalá Mateo, Bosque Sendra and Plata Rochas, 2008; Barreira González, González Cascón and Bosque Sendra, 2012; Diaz-Pacheco and Gutiérrez, 2013; Teixeira, Marques and Pontius Jr., 2016). The only exceptions are the work presented by García-Álvarez and Camacho Olmedo (2021) and the analysis of Ovejero-Campos et al. (2019). The first provides a general analysis of the CLC dataset for all Europe from 1990 to 2012, including some brief comments on the potential uncertainties of the changes mapped by the CLC time series. The second analyses the CORINE time series between 1990 and 2012 to evaluate its quality for LUC change analysis in coastal areas. None of both works evaluate the CORINE time series in detail and for general purposes, including both CORINE status layers and layers of changes. 
This manuscript has been submitted for publication in "International Journal of Remote Sensing". Subsequent versions of this manuscript, after acceptance and review by the journal, may have slightly different content. If accepted, the final version of this manuscript will be available via the 'Peer-reviewed Publication DOI'

Through this paper, we aim to fill the previous research gap by analyzing in detail the coherence and uncertainties of the CORINE Land Cover time series for Spain. We build on the previous work carried out by García-Álvarez and Camacho Olmedo (2017) and MartínezFernández et al. (2019), which have assessed in detail the uncertainty of CORINE for the period 2006-2012, when the method of production of CORINE for Spain changed. Since 2012, CORINE is obtained through generalization of SIOSE, a fine-scale national LUC database. However, the SIOSE method of production has also changed since the 2017 edition (Equipo Técnico Nacional SIOSE, 2020), which may have introduced changes in the last CORINE release as well. Thus, through the present paper, we aim to shed light on the uncertainties associated to the last update of CORINE for Spain at the same time that we analyze the full coherence and uncertainty of the Spanish CORINE time series.

To that end, we first provide a brief presentation of the CORINE Land Cover dataset, its history and characteristics. Second, we make a brief introduction to the selected study area (Asturias). In the third part of the paper, we explain the methods employed in our analysis. Later, the results are presented and discussed. Finally, we provide a brief conclusion.

\section{Corine Land Cover}

CORINE Land Cover is a European LUC dataset whose production dates back to 1985 (Büttner, 2014). Since then, 5 different editions of CORINE have been produced for the reference years 1990, 2000, 2006, 2012 and 2018 (European Environment Agency, 2021). New updates of CORINE are expected every 6 years (Büttner, 2014).

CORINE is produced at the national level under the coordination of the EEA, which defines the common characteristics of the dataset and ensures its coherence in border areas (European 
This manuscript has been submitted for publication in "International Journal of Remote Sensing". Subsequent versions of this manuscript, after acceptance and review by the journal, may have slightly different content. If accepted, the final version of this manuscript will be available via the 'Peer-reviewed Publication DOI'

Environment Agency, 2021). Nowadays, the CORINE production takes part of the Copernicus Land Monitoring Service, together with other relevant LUC products at finer (HRL, Urban Atlas...) and coarser scales (CGLS-LC100) (García-Álvarez and Florina Nanu, 2022). A new product based on the CORINE experience and complementary to it is currently being developed. CORINE Land Cover + (CLC+), also called the "2nd generation CORINE Land Cover", will provide a single repository of European and selected national LUC datasets, which will be integrated in a common grid following the EAGLE data model and nomenclature (Probeck et al., 2021). The created grid will be based on a new product (CLC+ Backbone) obtained through Sentinel imagery segmentation and auxiliary data, which will also classify the landscape through a 18-categories classification scheme (European Environment Agency, 2021). The new CLC+ dataset will allow its use for multiple purposes, including the update of the traditional CORINE dataset (CLC legacy).

CORINE maps have been traditionally obtained in vector format through photointerpretation of satellite imagery at 1:100.000 scale (Büttner, 2014). However, in the last decade, an increasing number of countries, including Spain, obtain CORINE through the generalization of national LUC datasets at finer scales (Hazeu et al., 2016). The Figure 1 shows the workflow for updating CORINE in Spain. Independent of the production method, CORINE mapping rules remain the same: a Minimum Mapping Unit (MMU) of 25ha, a Minimum Mapping Width (MMW) of 100m and a 3-level classification legend with a maximum disaggregation of 44 categories (European Environment Agency, 2021).

In addition to the production of a CORINE status layer (CLC), for each mapped period $(90 / 00,00 / 06,06 / 12,12 / 18)$ a specific layer of changes (CHA) is obtained. This layer maps all LUC changes over the considered period at the same scale and with a Minimum Mapping Unit of 
This manuscript has been submitted for publication in "International Journal of Remote Sensing". Subsequent versions of this manuscript, after acceptance and review by the journal, may have slightly different content. If accepted, the final version of this manuscript will be available via the 'Peer-reviewed Publication DOI'

only 5ha, except for the first period (90/00). Different to the comparison of the status layers, the CORINE layers of changes only map the changes that really happened on the ground, without any technical change due to mapping errors or changes in the method of production.

The CLC layers are obtained since 2006 from the revision of the previous CLC layer of reference and the superposition of the CHA layer (Fig. 1). In this regard, every time a new CLC status layer is produced, the one for the previous year is updated, accounting for the detected error and inconsistencies. Because of the different mapping rules between CLC and CHA layers, the updated CLC layer with CHA changes is generalized to fit with the CLC MMU rule.

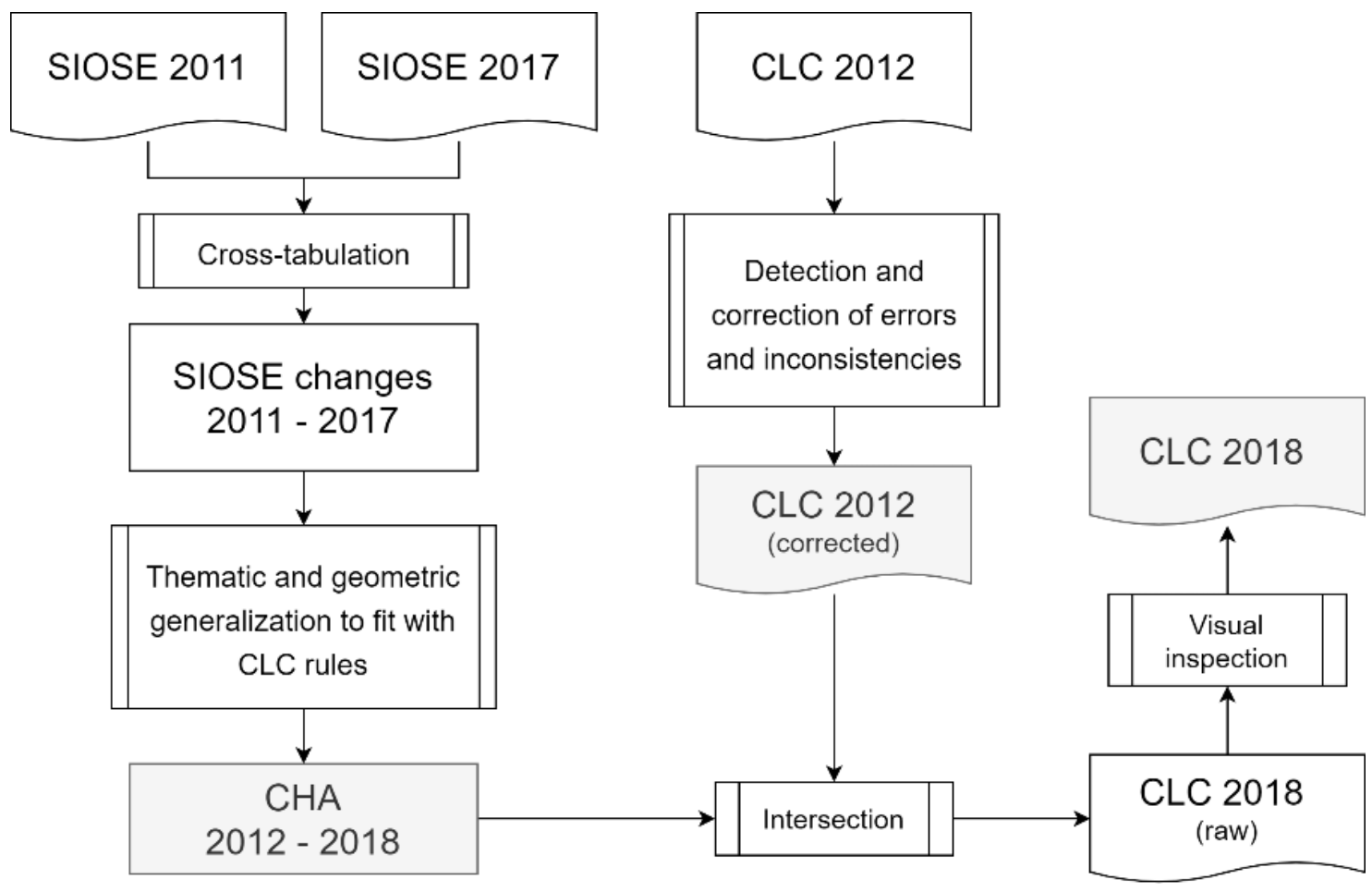

Figure 1. Updating workflow of CORINE in Spain

\section{Study area}

The Principality of Asturias is one of the 17 Spanish Autonomous Communities, the first level of 
This manuscript has been submitted for publication in "International Journal of Remote Sensing". Subsequent versions of this manuscript, after acceptance and review by the journal, may have slightly different content. If accepted, the final version of this manuscript will be available via the 'Peer-reviewed Publication DOI'

administrative division in Spain. It is located in North Spain, as part of the Cantabrian Coast (Fig. 2). Asturias is a mountainous region made up of a succession of mountain ranges and deep valleys plus a plain coastal surface where most of the activities and infrastructures locate (Cortizo Álvarez, Fernández García and Maceda Rubio, 1990). At the center of the region, in a topographically favorable area, the Asturias Central Area hosts the most relevant urban centers of Asturias as well as most of the population and economic activity (Rodríguez Gutiérrez, Menéndez Fernández and Blanco Fernández, 2009). Most of the artificial users and covers of the region are placed here and in the coast. On the contrary, the rest of Asturias and, especially, its mountainous areas, are dominated by rural and natural landscapes made up of pastures and forests (Rodríguez Gutiérrez and Menéndez Fernández, 2005). Because of the difficult topographic conditions, the agricultural activity of Asturias is mostly driven by extensive livestock farming, with limited surfaces of arable land (Cortizo Álvarez, Fernández García and Maceda Rubio, 1990).

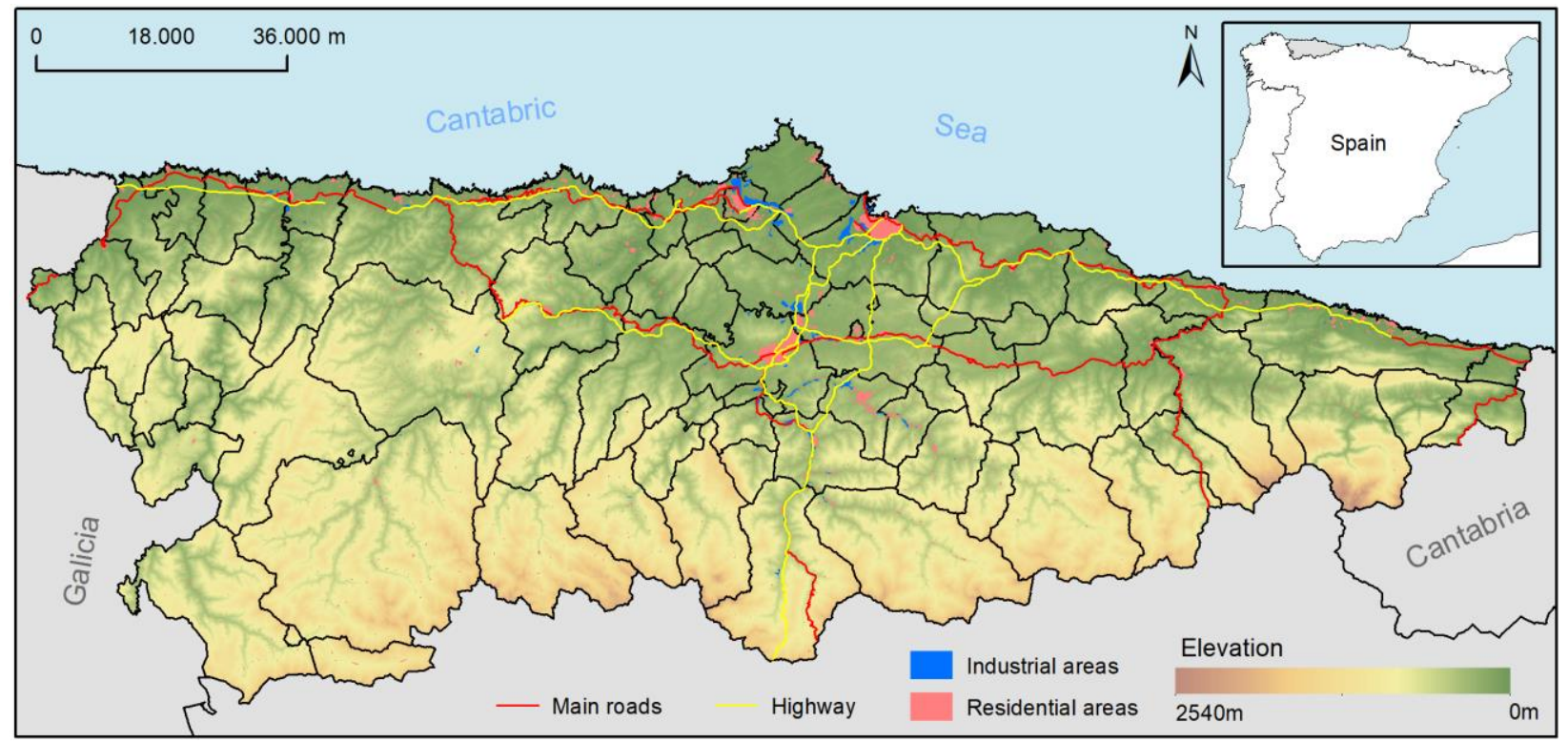

Figure 2. Location map of Asturias 
This manuscript has been submitted for publication in "International Journal of Remote Sensing". Subsequent versions of this manuscript, after acceptance and review by the journal, may have slightly different content. If accepted, the final version of this manuscript will be available via the 'Peer-reviewed Publication DOI'

\section{Methods}

We analyzed the changes showed by the CORINE Land Cover database in both the CORINE status layers (CLC) and the CORINE layers of changes (CHA). To this end, we made use of the available CLC and CHA layers for Spain: CLC90, CLC00, CHA00, CLC06, CHA06, CLC12, CHA12, CLC18 and CHA18. Figure 3 shows a flowchart of the approach followed to analyze these datasets.

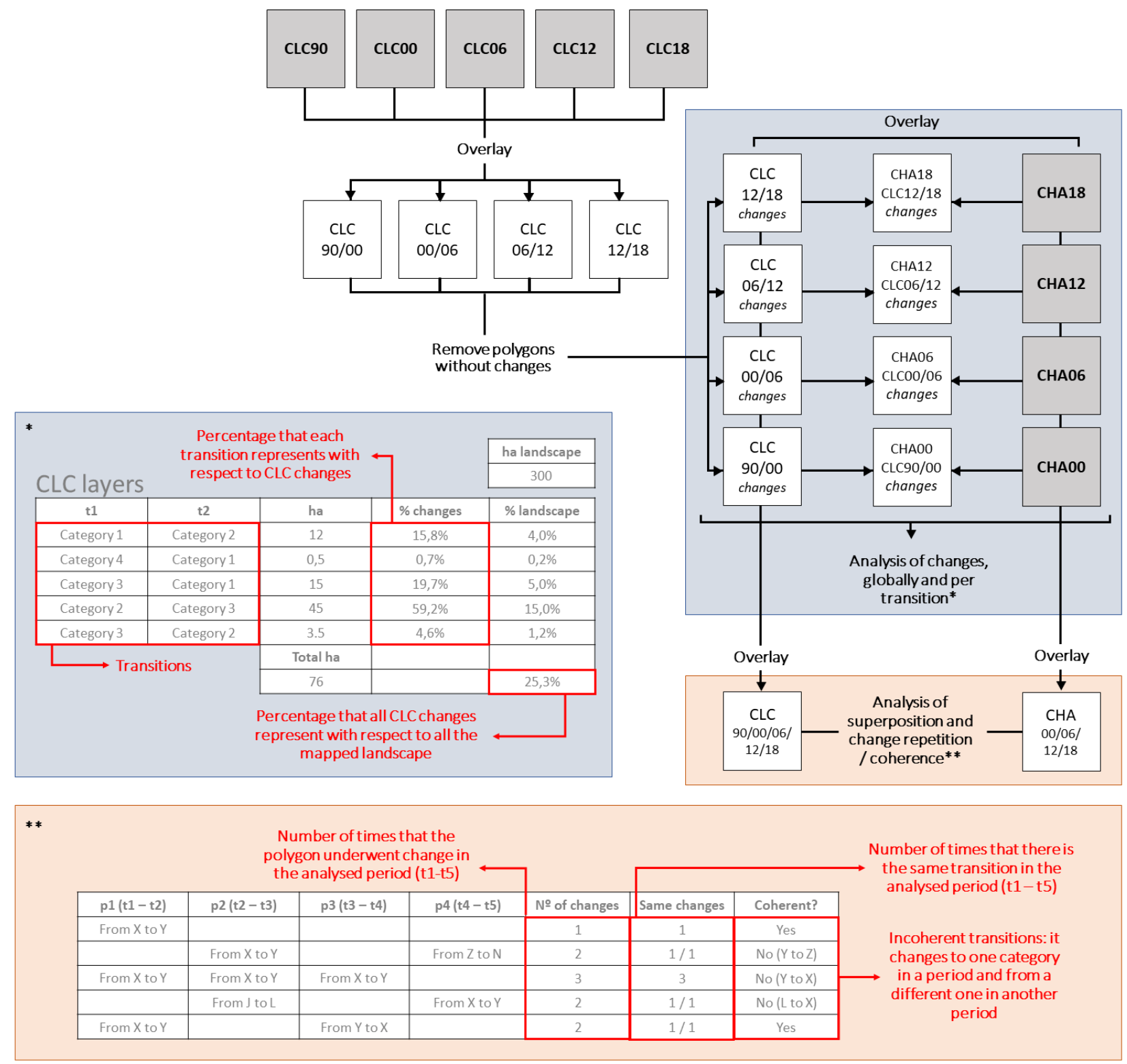


This manuscript has been submitted for publication in "International Journal of Remote Sensing". Subsequent versions of this manuscript, after acceptance and review by the journal, may have slightly different content. If accepted, the final version of this manuscript will be available via the 'Peer-reviewed Publication DOI'

Figure 3. Flowchart of the analysis of CORINE Land Cover data carried out for this study

CLC vector layers were overlayed in pairs, matching the periods for which CHA layers are available: 90/00, 00/06, 06/12 and 12/18. After the layers were overlaid, we separated those polygons that changed between dates from those ones that did not undergo change. Then, we analyzed the polygons that changed globally and per transition for each of the three levels of the CORINE classification legend. In each case, we calculated the area and proportion of the changes for all Asturias and with respect to the total quantity of detected changes for each period. Changes showed by CHA layers were analyzed in the same way: globally and per transition for all Asturias and with respect the total quantity of CHA changes for each available period.

To better understand the changes showed by the dataset and their nature, we have grouped the transitions of each CLC and CHA layer in five groups, according to the type of uses or covers involved: mixed covers, moors and heathland, pure forest covers, agricultural covers and artificial surfaces (Table 1). These groups include the most representative covers of LUC change in Asturias and reflect well the different nature and characteristics of the covers involved.

Table 1. List of land uses and covers according to the level 3 of the CORINE classification scheme for each of the five groups that we have analyzed: arable, artificial, forest, mixed covers and moors and heathland.

\begin{tabular}{|c|c|c|c|c|}
\hline Arable & Artificial & Forest & Mixed covers & $\begin{array}{c}\text { Moors and } \\
\text { heathland }\end{array}$ \\
\hline $\begin{array}{c}\text { Non-irrigated arable } \\
\text { land }\end{array}$ & $\begin{array}{c}\text { Continuous urban } \\
\text { fabric }\end{array}$ & Broad-leaved forest & $\begin{array}{c}\text { Complex cultivation } \\
\text { patterns }\end{array}$ & $\begin{array}{c}\text { Moors and } \\
\text { heathland }\end{array}$ \\
\hline $\begin{array}{c}\text { Permanently } \\
\text { irrigated land }\end{array}$ & $\begin{array}{c}\text { Discontinuous } \\
\text { urban fabric }\end{array}$ & Coniferous forest & $\begin{array}{c}\text { Land principally } \\
\text { occupied by } \\
\text { agriculture, with } \\
\text { significant areas of } \\
\text { natural vegetation }\end{array}$ & $\begin{array}{c}\text { Transitional } \\
\text { woodland-shrub }\end{array}$ \\
\hline Rice fields & $\begin{array}{c}\text { Industrial or } \\
\text { commercial units } \\
\text { Road and rail } \\
\text { networks and } \\
\text { associated land }\end{array}$ & & Mixed forest & \\
\hline
\end{tabular}


This manuscript has been submitted for publication in "International Journal of Remote Sensing". Subsequent versions of this manuscript, after acceptance and review by the journal, may have slightly different content. If accepted, the final version of this manuscript will be available via the 'Peer-reviewed Publication DOI'

\begin{tabular}{|c|c|l|c|c|}
\hline $\begin{array}{c}\text { Fruit trees and berry } \\
\text { plantations }\end{array}$ & Port areas & $\begin{array}{c}\text { Annual crops } \\
\text { associated with } \\
\text { permanent crops }\end{array}$ & \\
\hline Olive groves & Airports & & Agro-forestry areas & \\
\hline Pastures & $\begin{array}{c}\text { Mineral extraction } \\
\text { sites }\end{array}$ & & & \\
\hline & Dump sites & & & \\
\hline & Construction sites & & & \\
\hline & Green urban areas & & & \\
\hline & $\begin{array}{c}\text { Sport and leisure } \\
\text { facilities }\end{array}$ & & & \\
\hline
\end{tabular}

CHA and CLC change layers were also mutually overlaid in pairs to account for the changing areas that are included in the two layers, globally and per transition. We differentiated between those cases where the two layers show the same transitions and those cases where the two layers show different transitions.

Finally, CLC and CHA layers for all available periods were independently overlaid (CLC $\mathrm{t}_{1234}$ and $\left.\mathrm{CHA} \mathrm{t}_{1234}\right)$. This allowed to count the number of times a specific area underwent change in the considered period and the plausibility of the change timeseries for each case. In this regard, when the CLC and CHA layers showed a change from category $\mathrm{X}$ to category $\mathrm{Y}$ and the next change transitioned from a different category than $\mathrm{Y}$, this was considered a non-plausible change. In addition, we counted the number of times the same transition (e.g. from $\mathrm{X}$ to $\mathrm{Y}$ ) happened in the considered period.

\section{Results}

Except for the first editions of CORINE $(90,00)$, CLC layers always detect more LUC changes than CHA layers (Table 2). This is especially true in the 2012 and 2018 editions of CORINE: whereas CLC layers detect change in 36,5\% and 7,9\% of the mapped area for $2012(06 / 12)$ and 
This manuscript has been submitted for publication in "International Journal of Remote Sensing". Subsequent versions of this manuscript, after acceptance and review by the journal, may have slightly different content. If accepted, the final version of this manuscript will be available via the 'Peer-reviewed Publication DOI'

$2018(12 / 18)$ respectively, CHA layers only detect $1,3 \%$ and $1,1 \%$ of change for the same periods.

The 2000 edition of CORINE (90/00) is the only one for which the mapped changes by CLC layers are the same than the mapped changes by CHA layers.

Even despite the big difference in the quantity of detected changes, CLC layers do not even account for all changes mapped in the CHA layers. In 2012 and 2018, around a quarter of the mapped changes by CHA layers are not considered as changing areas in CLC layers (Table 2). In addition, when both layers consider change, that change is sometimes differently interpreted by each layer: in 2012 half of the changing areas mapped by both CLC and CHA layers showed a different transition of change in each case. In 2018, this happened the $25 \%$ of the times.

Table 2. Percent of detected changes, regarding the total mapped area, by the CORINE status layers (CLC) and the CORINE layers of changes (CHA). We differentiate between changes exclusively mapped by each layer (Only CLC, Only CHA) and changes mapped by the two layers (Both CLC\&CHA). Among the last ones, we differentiate between those cases where the two layers describe the change through the same or different transitions.

\begin{tabular}{|c|l|c|c|c|c|}
\hline & & $\mathbf{1 8} / \mathbf{1 2}$ & $\mathbf{1 2 / 0 6}$ & $\mathbf{0 6} / \mathbf{0 0}$ & $\mathbf{0 0 / 9 0}$ \\
\hline \multirow{3}{*}{ CLC } & Total & $7,9 \%$ & $36,5 \%$ & $1,6 \%$ & $2,3 \%$ \\
\cline { 2 - 5 } & Only CLC & $7,1 \%$ & $35,6 \%$ & $0,5 \%$ & $0,0 \%$ \\
\hline \multirow{2}{*}{ CHA } & Total & $1,1 \%$ & $1,3 \%$ & $1,2 \%$ & $2,3 \%$ \\
\cline { 2 - 6 } & Only CHA & $0,3 \%$ & $0,3 \%$ & $0,1 \%$ & $0,0 \%$ \\
\hline \multirow{2}{*}{$\begin{array}{c}\text { Both } \\
\text { CLC\&CHA) }\end{array}$} & Total & $0,8 \%$ & $1,0 \%$ & $1,1 \%$ & $2,3 \%$ \\
\cline { 2 - 6 } & Same transitions & $0,6 \%$ & $0,4 \%$ & $1,0 \%$ & $2,3 \%$ \\
\cline { 2 - 6 } & Different transitions & $0,2 \%$ & $0,5 \%$ & $0,1 \%$ & $0,0 \%$ \\
\hline
\end{tabular}

Whereas CHA layers show a similar trend of changes for all periods, except for the first one (9000), four years longer in time with respect to the others, there are important differences in the number of changes detected by CLC layers in each period. In 2000 (90/00), CLC and CHA layers 
This manuscript has been submitted for publication in "International Journal of Remote Sensing". Subsequent versions of this manuscript, after acceptance and review by the journal, may have slightly different content. If accepted, the final version of this manuscript will be available via the 'Peer-reviewed Publication DOI'

map the same change according to the same transitions (Table 2). In 2006 (00/06), CLC layers detect more changes than CHA layers, although the difference is not very relevant. However, in the last two editions of CORINE and, above all, in 2012, there is a huge difference between the quantity of change mapped by CLC and CHA layers. This explains how, in all periods, CLC layers map change in $41 \%$ of the mapped area and CHA layers only in 5\% of the mapped area (Table 3 ).

In most of the cases, either in CLC or CHA layers, changes only happen once in the same area in all the analyzed period (90-18). Nevertheless, the number of areas undergoing two different transitions in the considered period (90-18) is very relevant: $22 \%$ in CLC and $14.5 \%$ in CHA (Table 3). The areas that undergo three or the maximum of possible changes (4), although exist, are quantitatively of little relevance. In CLC layers, most of the areas that change in more than one period, undergo those changes in the last editions of CORINE $(2012,2018) .70 \%$ of the areas undergoing two transitions experiment these changes in the periods $06 / 12$ and $12 / 18$. On the contrary, for CHA layers, almost $50 \%$ of the areas undergoing two transitions experiment those changes in the periods $90 / 00$ and $00 / 06$.

Table 3. Areas that underwent change in the CORINE status layers (CLC) and the CORINE layers of changes (CHA) classified according the number of times they undergo any change, from 1 (one time period out of 4 ) to 4 (changes in all time periods). The last row summarizes the size of all areas that undergo any change in the analyzed period (1990-2018) and their proportion with respect to the total mapped area.

\begin{tabular}{|l|c|c|c|c|}
\hline & \multicolumn{2}{|c|}{ CHA } & \multicolumn{2}{c|}{ CLC } \\
\hline & ha & \% total changes & ha & \% total changes \\
\hline 1 time period & 48746,3 & $84,0 \%$ & 459614,2 & $76,9 \%$ \\
\hline 2 time periods & 13920,0 & $14,5 \%$ & 79586,6 & $22,0 \%$ \\
\hline 3 time periods & 674,7 & $1,3 \%$ & 7129,6 & $1,1 \%$ \\
\hline
\end{tabular}


This manuscript has been submitted for publication in "International Journal of Remote Sensing". Subsequent versions of this manuscript, after acceptance and review by the journal, may have slightly different content. If accepted, the final version of this manuscript will be available via the 'Peer-reviewed Publication DOI'

\begin{tabular}{|l|c|c|c|c|}
\hline 4 time periods & 29,4 & $0,1 \%$ & 782,0 & $0,0 \%$ \\
\hline & & \% total Asturias & & \% total Asturias \\
\hline All periods & 63370,5 & $4,8 \%$ & 547112,4 & $41,1 \%$ \\
\hline
\end{tabular}

CLC layers always show coherent transitions: there is one category in a date that transitions to a different category in the following date, which again transitions to the previous or another different category in the following date. However, that is not the case of CHA layers, although the areas that show these incoherencies only represent $2 \%$ (1279ha) of the mapped changes by CHA layers. Notwithstanding, there are important differences among years. Whereas the non-coherent transitions between CHA00 and CHA06 layers only cover 73,5ha, for the following periods the areas affected are much bigger: 750,8ha when comparing CHA12 and CHA06 layers and 454,6ha when comparing CHA18 and CHA12 layers. On the other hand, the proportion of changes, either in CLC or CHA layers, which are mapped following the same transition for more than one time point in the analyzed period (90-18) is insignificant: $1 \%(668,9 \mathrm{ha})$ of all mapped changes in CHA and $0,1 \%(662,5 \mathrm{ha})$ in CLC.

When analyzing the transitions mapped by each type of layer in detail, we can see how the exchanges among forest and semi natural areas are almost in all periods and layers (CLC, CHA) the most relevant change in quantity (Tables 4 and 5). These exchanges always represent above $70 \%$ of the mapped change in all CHA layers. In 2012 and 2018 CLC layers, they represent a smaller proportion because of the important number of changes among agricultural areas. The exchanges among forest and semi natural areas are usually from and to a couple categories: moors and heathland and transitional woodland-shrub (Table 6). 
This manuscript has been submitted for publication in "International Journal of Remote Sensing". Subsequent versions of this manuscript, after acceptance and review by the journal, may have slightly different content. If accepted, the final version of this manuscript will be available via the 'Peer-reviewed Publication DOI'

In 2012 and 2018, the exchanges among agricultural areas are one of the biggest changes detected by CLC layers (Table 5). These exchanges are not meaningfully mapped in any CHA layers, neither in the in previous editions of CORINE (1990-2006). In CLC layers, changes in agricultural areas represent a proportion of the mapped changes which is 7 (2018) and 3 (2012) times bigger than the proportion that the same type of changes represent in CHA layers and 3-4 times bigger than the same transitions in previous editions of CORINE (Table 5). The most important exchanges of agricultural covers mapped by CLC layers in 2012 and 2018 are the transitions from and to heterogeneous agricultural areas (that is, mixed covers), which in many cases are not even mapped at any extent in CHA layers (Table 6).

Table 4. Percent of detected changes, regarding the total of mapped changes and the total mapped area, by the CORINE status layers (CLC) and the CORINE layers of changes (CHA) differentiated according to the categories that take part of the change: mixed categories, moors and heathland, forest categories, agricultural categories and artificial surfaces (see Table 1). Color scales help to interpret the data: in the tables above the color scale is applied per row, whereas in the tables below it is applied per pairs of columns $(18 / 12,12 / 06 \ldots)$.

\begin{tabular}{|l|c|c|c|c|c|c|c|c|}
\hline & \multicolumn{4}{|c|}{ CLC (\% changes) } & \multicolumn{4}{c|}{ CHA (\% changes) } \\
\hline & $\mathbf{1 8 / 1 2}$ & $\mathbf{1 2 / 0 6}$ & $\mathbf{0 6 / 0 0}$ & $\mathbf{0 0 / 9 0}$ & $\mathbf{1 8 / 1 2}$ & $\mathbf{1 2 / 0 6}$ & $\mathbf{0 6 / 0 0}$ & $\mathbf{0 0 / 9 0}$ \\
\hline Mixed & $66,5 \%$ & $48,2 \%$ & $41,5 \%$ & $51,5 \%$ & $70,3 \%$ & $43,3 \%$ & $34,6 \%$ & $51,5 \%$ \\
\hline $\begin{array}{l}\text { Moors and } \\
\text { heathland }\end{array}$ & $22,0 \%$ & $40,0 \%$ & $38,4 \%$ & $46,2 \%$ & $21,6 \%$ & $38,4 \%$ & $33,2 \%$ & $46,2 \%$ \\
\hline Forest & $\mathbf{3 1 , 7 \%}$ & $38,8 \%$ & $\mathbf{4 2 , 4 \%}$ & $38,6 \%$ & $\mathbf{6 7 , 7 \%}$ & $35,3 \%$ & $\mathbf{3 2 , 2 \%}$ & $38,6 \%$ \\
\hline Agricultural & $\mathbf{5 2 , 2 \%}$ & $\mathbf{3 6 , 2 \%}$ & $14,6 \%$ & $12,9 \%$ & $\mathbf{6 , 9 \%}$ & $\mathbf{1 0 , 2 \%}$ & $11,6 \%$ & $12,9 \%$ \\
\hline Artificial & $7,1 \%$ & $\mathbf{3 , 2 \%}$ & $23,0 \%$ & $15,7 \%$ & $7,3 \%$ & $\mathbf{1 8 , 9 \%}$ & $23,1 \%$ & $15,6 \%$ \\
\hline & \multicolumn{3}{|c|}{ CLC (\% mapped area) } & & \multicolumn{5}{|c|}{ CHA (\% mapped area) } \\
\hline & $\mathbf{1 8} / \mathbf{1 2}$ & $\mathbf{1 2 / 0 6}$ & $\mathbf{0 6 / 0 0}$ & $\mathbf{0 0 / 9 0}$ & $\mathbf{1 8 / 1 2}$ & $\mathbf{1 2 / 0 6}$ & $\mathbf{0 6 / 0 0}$ & $\mathbf{0 0 / 9 0}$ \\
\hline Mixed & $5,3 \%$ & $17,6 \%$ & $0,7 \%$ & $1,2 \%$ & $0,8 \%$ & $0,6 \%$ & $0,4 \%$ & $1,2 \%$ \\
\hline $\begin{array}{l}\text { Moors and } \\
\text { heathland }\end{array}$ & $1,7 \%$ & $14,6 \%$ & $0,6 \%$ & $1,1 \%$ & $0,2 \%$ & $0,5 \%$ & $0,4 \%$ & $1,1 \%$ \\
\hline Forest & $2,5 \%$ & $14,2 \%$ & $0,7 \%$ & $0,9 \%$ & $0,8 \%$ & $0,5 \%$ & $0,4 \%$ & $0,9 \%$ \\
\hline Agricultural & $4,1 \%$ & $13,2 \%$ & $0,2 \%$ & $0,3 \%$ & $0,1 \%$ & $0,1 \%$ & $0,1 \%$ & $0,3 \%$ \\
\hline
\end{tabular}


This manuscript has been submitted for publication in "International Journal of Remote Sensing". Subsequent versions of this manuscript, after acceptance and review by the journal, may have slightly different content. If accepted, the final version of this manuscript will be available via the 'Peer-reviewed Publication DOI'

\begin{tabular}{|l|c|c|c|c|c|c|c|c|}
\hline Artificial & $0,6 \%$ & $1,2 \%$ & $0,4 \%$ & $0,4 \%$ & $0,1 \%$ & $0,2 \%$ & $0,3 \%$ & $0,4 \%$ \\
\hline
\end{tabular}

Both changes of agricultural and forest and semi-natural covers are mostly driven by the dynamism of mixed categories. In this regard, the most relevant mapped transitions in any period in either CLC and CHA layers are from or to a mixed category (Table 4). Transitional woodlandshrub is the forest and semi-natural mixed cover accounting for all these changes. Among agricultural covers, complex cultivation patterns and land principally occupied by agriculture are the two categories accounting for all this change (Table 6).

Among artificial areas, mines, dump and construction sites are the covers that usually account for most of the mapped changes (Table 6). In the 2000 and 2006 editions of CORINE, changes in artificial areas represent an important part of the mapped changes in both CLC and CHA layers (Table 4). In 2018, the artificial surfaces only represent a small proportion of all changes $(7 \%)$ in both layers. In 2012, whereas changes in artificial areas represent 18,9\% of all CHA changes, they only represent the $3,2 \%$ of all CHA changes (Table 4). In area (ha), the differences are not that noticeable. However, when analyzing the specific transitions mapped by each layer, we can appreciate how CHA transitions from and to mine, dump and construction sites are 2-5 times bigger than the same transitions in CLC layers (Table 6).

Similar to the artificial areas case in 2012, forest covers (coniferous, broad-leaved forest) account for $67.7 \%$ of the CHA change in 2018 and only $31.7 \%$ in CLC (Table 4). However, CLC layers also map at a similar extent (area) the transitions in which forest covers are involved. Thus, this difference is proportion is not caused by many features mapped in CHA layers and not mapped in CLC layers, but because of the mapping of some specific transitions in CLC layers that are of little relevance or do not even exist in CHA layers. 
This manuscript has been submitted for publication in "International Journal of Remote Sensing". Subsequent versions of this manuscript, after acceptance and review by the journal, may have slightly different content. If accepted, the final version of this manuscript will be available via the 'Peer-reviewed Publication $D O I^{\prime}$

Table 5. Main transitions at the L1 Corine Land Cover classification level for the CORINE status layers (CLC) and the CORINE layers of changes (CHA) for each mapped period (12/18, 06/12, 00/06, 90-00). We indicate the percentage that each transition represents with respect to the total of mapped changes (DIF \%, CHA \%) as well as the ratio between the area of mapped changes by CLC and CHA layers (DIF/CHA) and by CHA and CLC layers (CHA/DIF). A DIF/CHA value of 757 means that the area of the considered transition in CLC layers is757 times the area of the considered transition in CHA layers.

\begin{tabular}{|c|c|c|c|c|c|c|c|}
\hline \multicolumn{2}{|c|}{ CLC transition } & \multirow{3}{*}{$\begin{array}{l}\text { DIF \% } \\
41,1 \%\end{array}$} & \multicolumn{2}{|c|}{ CHA transition } & \multirow{3}{*}{$\begin{array}{c}\text { CHA \% } \\
0,4 \%\end{array}$} & \multirow{3}{*}{$\begin{array}{c}\text { DIF/CHA } \\
758\end{array}$} & \multirow{3}{*}{$\begin{array}{c}\text { CHA/DIF } \\
0\end{array}$} \\
\hline \multicolumn{4}{|c|}{ 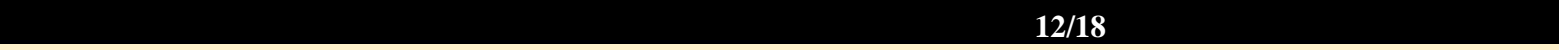 } & & & & \\
\hline Agricultural & Agricultural & & Agricultural & Agricultural & & & \\
\hline Forest and semi natural & Forest and semi natural & $32,8 \%$ & Forest and semi natural & Forest and semi natural & $\mathbf{8 7 , 8 \%}$ & 3 & 0 \\
\hline Forest and semi natural & Agricultural & $12,0 \%$ & Forest and semi natural & Agricultural & $4,5 \%$ & 19 & 0 \\
\hline Artificial & Artificial & $1,2 \%$ & Artificial & Artificial & $4,7 \%$ & 2 & 1 \\
\hline \multicolumn{8}{|c|}{$06 / 12$} \\
\hline Agricultural & Agricultural & $23,5 \%$ & Agricultural & Agricultural & $2,6 \%$ & 255 & 0 \\
\hline Agricultural & Forest and semi natural & $14,1 \%$ & Agricultural & Forest and semi natural & $\mathbf{0 , 8 \%}$ & 530 & 0 \\
\hline Forest and semi natural & Agricultural & $\mathbf{7 , 9 \%}$ & Forest and semi natural & Agricultural & $3,2 \%$ & 71 & 0 \\
\hline Artificial & Artificial & $1,1 \%$ & Artificial & Artificial & $5,6 \%$ & 5 & 0 \\
\hline Agricultural & Artificial & $1,0 \%$ & Agricultural & Artificial & $6,0 \%$ & 5 & 0 \\
\hline Forest and semi natural & Artificial & $0,3 \%$ & Forest and semi natural & Artificial & $4,5 \%$ & 2 & 1 \\
\hline Forest and semi natural & Forest and semi natural & $66,7 \%$ & Forest and semi natural & Forest and semi natural & $70,0 \%$ & 1 & 1 \\
\hline Agricultural & Artificial & $9,1 \%$ & Agricultural & Artificial & $\mathbf{7 , 9 \%}$ & 2 & 1 \\
\hline Forest and semi natural & Agricultural & $6,4 \%$ & Forest and semi natural & Agricultural & $4,0 \%$ & 2 & 0 \\
\hline Artificial & Forest and semi natural & $5,5 \%$ & Artificial & Forest and semi natural & $7,4 \%$ & 1 & 1 \\
\hline Artificial & Artificial & $5,1 \%$ & Artificial & Artificial & $3,3 \%$ & 2 & 0 \\
\hline Agricultural & Agricultural & $0,6 \%$ & & & & & \\
\hline \multicolumn{8}{|c|}{$90 / 00$} \\
\hline Forest and semi natural & Forest and semi natural & $72,7 \%$ & Forest and semi natural & Forest and semi natural & $72,7 \%$ & 1 & 1 \\
\hline
\end{tabular}


This manuscript has been submitted for publication in "International Journal of Remote Sensing". Subsequent versions of this manuscript, after acceptance and review by the journal, may have slightly different content. If accepted, the final version of this manuscript will be available via the 'Peer-reviewed Publication $D O I^{\prime}$

\begin{tabular}{|c|c|c|c|c|c|c|c|}
\hline Forest and semi natural & Agricultural & $8,4 \%$ & Forest and semi natural & Agricultural & $8,4 \%$ & 1 & 1 \\
\hline Agricultural & Artificial & $6,8 \%$ & Agricultural & Artificial & $6,8 \%$ & 1 & 1 \\
\hline Forest and semi natural & Artificial & $5,2 \%$ & Forest and semi natural & Artificial & $5,2 \%$ & 1 & 1 \\
\hline Artificial & Artificial & $2,4 \%$ & Artificial & Artificial & $2,4 \%$ & 1 & 1 \\
\hline Agricultural & Agricultural & $1,1 \%$ & Agricultural & Agricultural & $1,1 \%$ & 1 & 1 \\
\hline
\end{tabular}

Table 6. Main transitions at the L2-L3 Corine Land Cover classification levels for the CORINE status layers (CLC) and the CORINE layers of changes (CHA) for each mapped period (12/18, 06/12, 00/06, 90-00). Separate tables with all transitions for each level of the CORINE classification scheme are provided as supplementary material in the online version of this paper.

We indicate the percentage that each transition represents with respect to the total of mapped changes (DIF \%, CHA \%) as well as the ratio between the area of mapped changes by CLC and CHA layers (DIF/CHA) and by CHA and CLC layers (CHA/DIF). A DIF/CHA value of 757 means that the area of the considered transition in CLC layers is 757 times the area of the considered transition in CHA layers.

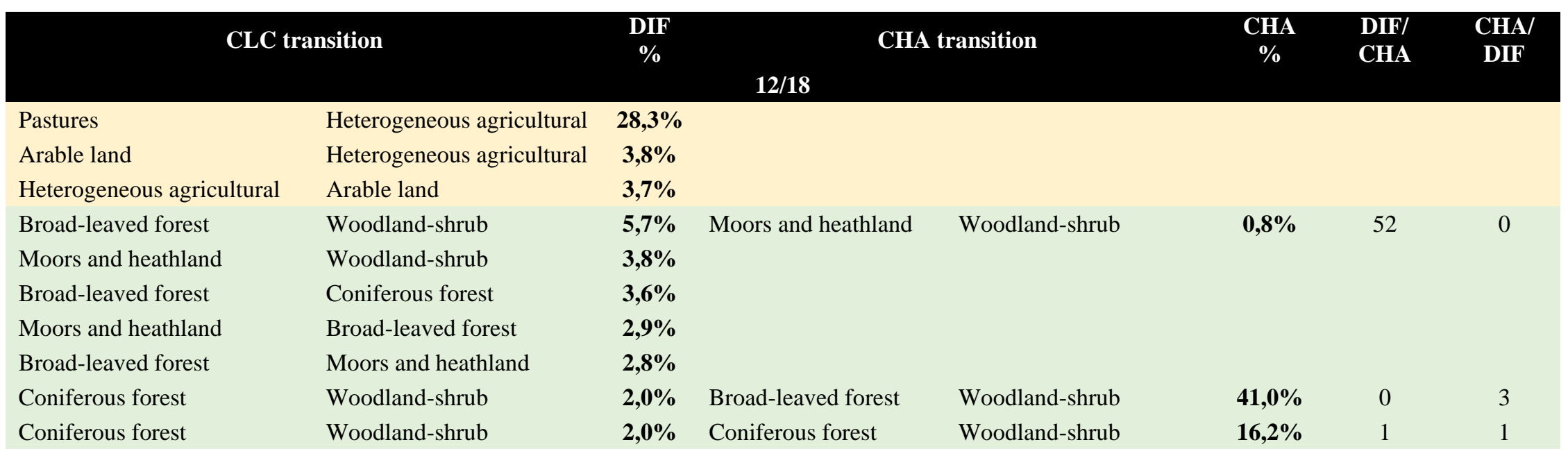


This manuscript has been submitted for publication in "International Journal of Remote Sensing". Subsequent versions of this manuscript, after acceptance and review by the journal, may have slightly different content. If accepted, the final version of this manuscript will be available via the 'Peer-reviewed Publication $D O I^{\prime}$

\begin{tabular}{|c|c|c|c|c|c|c|c|}
\hline Burnt areas & Moors and heathland & $1,3 \%$ & Burnt areas & Moors and heathland & $11,1 \%$ & 1 & 1 \\
\hline Woodland-shrub & Broad-leaved forest & $0,5 \%$ & Woodland-shrub & Broad-leaved forest & $6,4 \%$ & 1 & 2 \\
\hline Forests & Heterogeneous agricultural & $4,2 \%$ & \multirow{3}{*}{$\begin{array}{l}\text { Scrub/herbaceous } \\
\text { vegetation }\end{array}$} & \multirow{3}{*}{ Pastures } & \multirow{3}{*}{$4,3 \%$} & \multirow{3}{*}{5} & \multirow{3}{*}{0} \\
\hline Scrub/herbaceous vegetation & Pastures & $3,2 \%$ & & & & & \\
\hline Scrub/herbaceous vegetation & Heterogeneous agricultural & $2,2 \%$ & & & & & \\
\hline Mine, dump, construction & $\begin{array}{l}\text { Industrial, commercial, } \\
\text { transport }\end{array}$ & $0,5 \%$ & $\begin{array}{l}\text { Mine, dump, } \\
\text { construction }\end{array}$ & $\begin{array}{l}\text { Industrial, commercial, } \\
\text { transport }\end{array}$ & $4,3 \%$ & 1 & 1 \\
\hline \multicolumn{8}{|c|}{$06 / 12$} \\
\hline Woodland-shrub & Moors and heathland & $9,0 \%$ & Woodland-shrub & Moors and heathland & $0,5 \%$ & 467 & 0 \\
\hline Broad-leaved forest & Moors and heathland & $7,1 \%$ & Broad-leaved forest & Moors and heathland & $0,2 \%$ & 1007 & 0 \\
\hline Moors and heathland & Broad-leaved forest & $4,6 \%$ & Moors and heathland & Broad-leaved forest & $0,1 \%$ & 1969 & 0 \\
\hline Moors and heathland & Burnt areas & $\mathbf{0 , 0 \%}$ & Moors and heathland & Burnt areas & $13,4 \%$ & 0 & 12 \\
\hline Broad-leaved forest & Woodland-shrub & $0,6 \%$ & Broad-leaved forest & Woodland-shrub & $10,8 \%$ & 1 & 1 \\
\hline Moors and heathland & Sparsely vegetated areas & $0,3 \%$ & Moors and heathland & Sparsely vegetated areas & $8,6 \%$ & 1 & 1 \\
\hline Woodland-shrub & Coniferous forest & $0,6 \%$ & Woodland-shrub & Coniferous forest & $5,8 \%$ & 3 & 0 \\
\hline Woodland-shrub & Mixed forest & $0,4 \%$ & Woodland-shrub & Mixed forest & $4,1 \%$ & 3 & 0 \\
\hline Pastures & Arable land & $8,2 \%$ & Pastures & Arable land & $1,1 \%$ & 203 & 0 \\
\hline Pastures & Heterogeneous agricultural & $6,2 \%$ & Pastures & $\begin{array}{l}\text { Heterogeneous } \\
\text { agricultural }\end{array}$ & $0,2 \%$ & 730 & 0 \\
\hline Heterogeneous agricultural & Arable land & $5,1 \%$ & $\begin{array}{l}\text { Heterogeneous } \\
\text { agricultural }\end{array}$ & Arable land & $0,0 \%$ & 27429 & 0 \\
\hline Heterogeneous agricultural & Pastures & $3,6 \%$ & & & & & \\
\hline Heterogeneous agricultural & Forests & $4,4 \%$ & $\begin{array}{l}\text { Heterogeneous } \\
\text { agricultural }\end{array}$ & Forests & $0,3 \%$ & 366 & 0 \\
\hline Pastures & Forests & $4,2 \%$ & Pastures & Forests & $0,1 \%$ & 1656 & 0 \\
\hline Heterogeneous agricultural & $\begin{array}{l}\text { Scrub/herbaceous } \\
\text { vegetation }\end{array}$ & $2,9 \%$ & $\begin{array}{l}\text { Heterogeneous } \\
\text { agricultural }\end{array}$ & $\begin{array}{l}\text { Scrub/herbaceous } \\
\text { vegetation }\end{array}$ & $0,1 \%$ & 598 & 0 \\
\hline Pastures & $\begin{array}{l}\text { Scrub/herbaceous } \\
\text { vegetation }\end{array}$ & $2,7 \%$ & Pastures & $\begin{array}{l}\text { Scrub/herbaceous } \\
\text { vegetation }\end{array}$ & $0,1 \%$ & 627 & 0 \\
\hline Mine, dump, construction & $\begin{array}{l}\text { Industrial, commercial, } \\
\text { transport }\end{array}$ & $0,0 \%$ & $\begin{array}{l}\text { Mine, dump, } \\
\text { construction }\end{array}$ & $\begin{array}{l}\text { Industrial, commercial, } \\
\text { transport }\end{array}$ & $2,6 \%$ & 0 & 4 \\
\hline Pastures & Mine, dump, construction & $0,0 \%$ & Pastures & $\begin{array}{l}\text { Mine, dump, } \\
\text { construction }\end{array}$ & $2,4 \%$ & 0 & 2 \\
\hline
\end{tabular}


This manuscript has been submitted for publication in "International Journal of Remote Sensing". Subsequent versions of this manuscript, after acceptance and review by the journal, may have slightly different content. If accepted, the final version of this manuscript will be available via the 'Peer-reviewed Publication $D O I^{\prime}$

\begin{tabular}{|c|c|c|c|c|c|c|c|}
\hline Scrub/herbaceous vegetation & Mine, dump, construction & $\mathbf{0 , 0 \%}$ & $\begin{array}{l}\text { Scrub/herbaceous } \\
\text { vegetation }\end{array}$ & $\begin{array}{l}\text { Mine, dump, } \\
\text { construction }\end{array}$ & $1,9 \%$ & 0 & 2 \\
\hline Forests & Mine, dump, construction & $\mathbf{0 , 0 \%}$ & Forests & $\begin{array}{l}\text { Mine, dump, } \\
\text { construction }\end{array}$ & $1,8 \%$ & 0 & 2 \\
\hline Mine, dump, construction & Urban fabric & $\mathbf{0 , 0 \%}$ & $\begin{array}{l}\text { Mine, dump, } \\
\text { construction }\end{array}$ & Urban fabric & $1,6 \%$ & 0 & 5 \\
\hline \multicolumn{8}{|c|}{$00 / 06$} \\
\hline Burnt areas & Moors and heathland & $16,0 \%$ & Burnt areas & Moors and heathland & $21,6 \%$ & 1 & 1 \\
\hline Broad-leaved forest & Woodland-shrub & $8,6 \%$ & Broad-leaved forest & Woodland-shrub & $15,3 \%$ & 1 & 1 \\
\hline Coniferous forest & Woodland-shrub & $7,0 \%$ & Coniferous forest & Woodland-shrub & $10,0 \%$ & 1 & 1 \\
\hline Woodland-shrub & Broad-leaved forest & $5,9 \%$ & Woodland-shrub & Broad-leaved forest & $4,1 \%$ & 2 & 1 \\
\hline Moors and heathland & Woodland-shrub & $5,2 \%$ & Moors and heathland & Woodland-shrub & $1,7 \%$ & 4 & 0 \\
\hline Broad-leaved forest & Moors and heathland & $3,6 \%$ & & & & & \\
\hline Coniferous forest & Moors and heathland & $3,0 \%$ & & & & & \\
\hline Pastures & Urban fabric & $3,3 \%$ & Pastures & Urban fabric & $0,9 \%$ & 5 & 0 \\
\hline Pastures & Mine, dump, construction & $2,2 \%$ & Pastures & $\begin{array}{l}\text { Mine, dump, } \\
\text { construction }\end{array}$ & $4,0 \%$ & 1 & 1 \\
\hline Pastures & $\begin{array}{l}\text { Industrial, commercial, } \\
\text { transport }\end{array}$ & $2,0 \%$ & & & & & \\
\hline Mine, dump, construction & $\begin{array}{l}\text { Scrub/herbaceous } \\
\text { vegetation }\end{array}$ & $5,2 \%$ & $\begin{array}{l}\text { Mine, dump, } \\
\text { construction }\end{array}$ & $\begin{array}{l}\text { Scrub/herbaceous } \\
\text { vegetation }\end{array}$ & $7,3 \%$ & 1 & 1 \\
\hline
\end{tabular}


This manuscript has been submitted for publication in "International Journal of Remote Sensing". Subsequent versions of this manuscript, after acceptance and review by the journal, may have slightly different content. If accepted, the final version of this manuscript will be available via the 'Peer-reviewed Publication DOI'

\section{Discussion}

The results prove how CLC and CHA layers provide very different information for Land Use Cover Change (LUCC) analysis. However, this difference is especially noticeable since 2012, after the change of production of CORINE Spain, which has introduced important limitations in the use of the CORINE temporal series. In all cases, mixed categories account for most of the mapped change, which may introduce new uncertainties in our studies because of the flexible nature of these categories and the difficulty to define them with precision. In the next sections, we independently address each of these issues.

\section{The difference between CLC and CHA layers}

The EEA and the CORINE production teams advise to use the CHA layers of CORINE for LUC change analysis as CLC layers include technical changes caused by the correction of detected errors or variations in the method of production (European Environment Agency, 2021). Our results prove how LUC change analysis from CLC and CHA layers may end in very different results and conclusions.

The only exception to that general rule are the CLC layers for the two first years that CORINE is available $(1990,2000)$. Changes from the comparison of CLC layers for these years are the same than the changes mapped by the CHA layer for that period. This is explained by the specificity of the first CORINE update. The first CHA layer was obtained in some countries from the intersection of CLC90 and CLC00, after the revision of the first layer (Büttner, 2014; European Environment Agency, 2021). Thence, there are not differences between CLC and CHA changes as both were obtained in the same way. Nonetheless, this means that CHA90 does not fit the 5ha MMU of CHA layers. 
This manuscript has been submitted for publication in "International Journal of Remote Sensing". Subsequent versions of this manuscript, after acceptance and review by the journal, may have slightly different content. If accepted, the final version of this manuscript will be available via the 'Peer-reviewed Publication DOI'

Since 2006, the "change mapping first" approach has been the compulsory method established by the EEA for updating CORINE (Büttner and Kosztra, 2011): changes are first obtained by photointerpretation or generalization of finer databases and the new CLC layer is later obtained through the combination of the previous CLC layer, once the detected errors and inconsistences have been corrected, and the new layer of changes. Then, the obtained CLC layer is generalized to fit the MMU of CLC layers (25ha). This explains the differences between CLC and CHA layers in the 2006 edition. Although there are some differences in the information that they show, the pattern and sizes of the changes measured by both types of layers is very similar. Therefore, disagreements can be attributed to the generalization process.

Opposite to the previous differences, CLC and CHA layers in 2012 and 2018 show very different transitions and sizes of changes. In addition, a relevant part of the changes mapped by CHA layers in those years are not included or coded differently in CLC layers. In this regard, in 2012 more than half of the changed mapped in the CHA layers is wrongly represented or not represented in the CLC layer. These disagreements cannot be explained by the generalization carried out when producing the CLC layers. It can only be explained by the variations in the method of production of the Spanish CORINE, which affected not only to the areas that underwent change, but to all the mapped landscape (section 6.2).

Despite of the official recommendations to use CHA layers for change analysis instead of CLC layers, it is still common the use of the last ones for LUC change analysis (Hewitt and Escobar, 2011; Rusu et al., 2020; Fernández Nogueira, 2021; Gemitzi et al., 2021). As the first editions of CORINE (up to 2006) did not show big differences between using one or the other layers for LUC change analysis, users were not faced with the same 
This manuscript has been submitted for publication in "International Journal of Remote Sensing". Subsequent versions of this manuscript, after acceptance and review by the journal, may have slightly different content. If accepted, the final version of this manuscript will be available via the 'Peer-reviewed Publication DOI'

uncertainties than they find now. This may explain that the use of CLC layers to assess LUC changes has remained a common practice along time. Thence, users require of more and better information regarding the correct use of CORINE database. Although the EEA and the Copernicus programme already provide relevant documentation, the national authorities in charge of CORINE production and distribution, such as the Instituto Geográfico Nacional (IGN) in Spain, supply very limited information on the database and do not warn about all these issues. In this regard, the Spanish IGN does not even provide with the last release of CORINE the most updated product manual (European Environment Agency, 2021), where all these issues are addressed in detail.

Many users still require a coherent time series of CLC layers. In this regard, in many cases, the CLC time series is used as an auxiliary layer for different mapping methodologies or as a required input for different spatial analyses (Burkhard et al., 2012; Goerlich and Cantarino, 2013; Kucsicsa et al., 2019). Other users demand to study LUC change for larger periods than the ones between CORINE editions. The EEA has recently developed a coherent time series of raster CLC layers to fit these user needs: the CLC accounting layers (European Environment Agency, 2021). They are obtained by backdating the last CLC layer (2018) with the information provided by the CHA layers.

The CLC accounting layers present a triple limitation. First, they are only produced in raster format at $100 \mathrm{~m}$, which may not fit the requirements of all the CORINE user community. Although more time and resource-consuming, the development of a similar product in vector format, the traditional one in which CORINE is distributed, could better satisfy the needs of users and favor the correct use of the dataset. Second, CLC accounting layers present MMU inconsistencies, with many patches below the 25ha threshold (European Environment Agency, 2021). This is of little relevance for many 
This manuscript has been submitted for publication in "International Journal of Remote Sensing". Subsequent versions of this manuscript, after acceptance and review by the journal, may have slightly different content. If accepted, the final version of this manuscript will be available via the 'Peer-reviewed Publication DOI'

users of CORINE, but could be relevant for those users interested in knowing the distribution of land uses and covers through time, which need coherent measurement rules across the different years. Finally, when there are incoherencies between CHA layers, these are translated to CLC accounting layers as well. The CORINE production team has already tested a method to correct this inconsistencies, although it has not been approved and applied yet (European Environment Agency, 2021). Nonetheless, previous experiences with the two first CHA layers show the path to follow, which does not demand a lot of effort nor time (Maucha, Büttner and Pataki, 2011). In this regard, as our study showed, the number of changes that present these inconsistences is very low, only affecting a very small proportion of the detected changes in CHA layers. It would only require a small investment to correct these errors in the original $\mathrm{CHA}$ layers, avoiding these sources of uncertainty for any user of the CORINE database.

\section{The changes in the method of production of CORINE Spain and their effects}

Since 2012, CORINE has been produced in Spain from the generalization of the national LUC database of reference: SIOSE (García-Álvarez and Camacho Olmedo, 2017). Before, it was manually obtained through photointerpretation of satellite imagery. That variation caused a lot of changes in the CORINE dataset for Spain, as studied in detail by García-Álvarez and Camacho Olmedo (2017) and Martínez-Fernández et al. (2019). Their studies show how the Spanish landscapes are differently conceptualized in terms of covers and uses in the CORINEs before and after 2012, which explains the important differences between CLC and CHA layers for the period 2006-2012 that we have detected. Our analysis showed how, different to previous editions, agricultural areas and, specifically, heterogeneous agricultural areas, have gained more relevance in recent CORINE editions of Spain. In addition to this allocation disagreement, the detail of the 
This manuscript has been submitted for publication in "International Journal of Remote Sensing". Subsequent versions of this manuscript, after acceptance and review by the journal, may have slightly different content. If accepted, the final version of this manuscript will be available via the 'Peer-reviewed Publication DOI'

dataset did also vary, with the new CORINEs showing more complex polygons, that not always comply with the CORINE MMU and MMW rules (García-Álvarez and Camacho Olmedo, 2017). Some inconsistencies in the landscape conceptualization have been also detected, such as the interpretation of areas made up of a mixture of not related artificial covers as urban fabric.

The change of methodology of CORINE in Spain affected the production of both CLC and CHA layers, although the analyses of García-Álvarez and Camacho Olmedo (2017) and Martínez-Fernández et al. (2019) have only focused on the former ones. CHA layers are also obtained through the generalization of SIOSE changes (European Environment Agency, 2021). In this regard, if there are important differences in the complexity and conceptualization of the CLC layers before and after the methodology change, it is expected that the changes showed by CHA layers will be affected by these methodological differences as well. In this regard, our analysis proved how the number of non-coherent transition between CHA layers before and after the CORINE 2012 edition is up to 10 times bigger than between $\mathrm{CHA}$ layers prior to the methodology change. Thence, a detailed analysis of the effects of the methodology change of CORINE on the mapping of areas of change is required, as it would allow to understand the potential uncertainties of other products, such as the CLC accounting layers. Thus, even if CHA layers do not include technical changes, the transitions and categories that transition may be differently interpreted in one and other year, which makes the interyear comparison uncertain.

The last edition of CORINE (2018) followed in Spain the same methodology than in the 2012 edition. However, important differences remain between the changes showed by CLC and CHA layers. This may be caused by the change in the method of production 
This manuscript has been submitted for publication in "International Journal of Remote Sensing". Subsequent versions of this manuscript, after acceptance and review by the journal, may have slightly different content. If accepted, the final version of this manuscript will be available via the 'Peer-reviewed Publication DOI'

of SIOSE (Delgado Hernández et al., 2017). Since 2017, SIOSE has been rebranded as SIOSE Alta Resolución (AR) (SIOSE High Resolution) and is being produced at very detailed scales and with finer MMU and MMW through the integration of national and regional spatial databases, such as the Spanish cadastre, the information collected as part of the Common Agricultural Policy (CAP) campaigns, LiDAR data or the Spanish forest map (Equipo Técnico Nacional SIOSE, 2020). Before, SIOSE was obtained from manual phointerpretation of aerial imagery (Valcárcel Sanz and Castaño Fernández, 2012). As far as SIOSE editions before and after 2017 have been obtained following different methods, there will be important differences among them, which will be also translated to the updating workflow of CORINE.

Although not that relevant and massive as in 2012, CLC layers between 2018 and 2012 show important areas of disagreement (up to $7 \%$ of the mapped surface) that cannot be attributed to LUC changes. Most of this disagreement is between agricultural areas and usually involve mixed agricultural covers, such as complex cultivation patterns and land principally occupied by agriculture, with significant areas of natural vegetation. This is a common feature of the technical changes between 2012 and 2006 caused by the CORINE methodology change (García-Álvarez and Camacho Olmedo, 2017). In both cases we find a lot of technical changes that involve agricultural covers, despite these changes and exchanges among agricultural covers are usually irrelevant in the real landscapes, as reflected by the CHA layers.

Semi-automatic approaches for CORINE production are becoming more common across the different European countries, although the traditional photointerpretation remains the norm (European Environment Agency, 2021). However, when making these methodological changes, official documentation should be provided on the new methods 
This manuscript has been submitted for publication in "International Journal of Remote Sensing". Subsequent versions of this manuscript, after acceptance and review by the journal, may have slightly different content. If accepted, the final version of this manuscript will be available via the 'Peer-reviewed Publication DOI'

that have been implemented and their consequences on the database. Four years after the first studies showing the consequences of the new production method in the Spanish CORINE were published, official documentation about this methodological change is very scarce and only available at the European level, as part of general descriptions and comments on the database produced by the EEA in the context of the Copernicus Land programme (European Environment Agency, 2021). For Spain, the IGN, in charge of producing CORINE and carrying out its generalization from SIOSE, has not produced any documentation on the change of methodology and its consequences, which makes the understanding of the database's uncertainty harder for any interested user. For the least release of CORINE (2018), no information is available at any level explaining the technical changes between CLC layers from 2018 and 2012.

Semi-automated methodologies for change mapping may introduce important changes in the key deliverables of the CORINE time series and cannot be totally suitable for LUCC mapping. In this regard, the last CORINE user manual points how the delineation and interpretation of LUC changes require local knowledge and a degree of abstraction that is difficult to achieve through semi-automated approaches (European Environment Agency, 2021). The Portuguese experience, based on the automatic detection of changes for further manual photointerpretation, may be a balanced solution to update CORINE ensuring its historical coherence and consistency.

\section{The problem of mixed categories}

When mapping landscapes at coarse scales, mixed categories are usually required to define areas made up of a mixture of different land uses or covers that cannot be attributed to a single one (Villa et al., 2008; Valcárcel Sanz and Castaño Fernández, 2012). However, these categories come with important limitations, usually because of their 
This manuscript has been submitted for publication in "International Journal of Remote Sensing". Subsequent versions of this manuscript, after acceptance and review by the journal, may have slightly different content. If accepted, the final version of this manuscript will be available via the 'Peer-reviewed Publication DOI'

imprecise definitions, as they are created with a general purpose, to host different associations of uses and covers (Valcárcel Sanz and Castaño Fernández, 2012). Because of the absence of clear rules to define what a mixed category is, important variations may arise between mapping exercises from different users or following different methods. In addition, because of that flexibility, mapping LUC change is also very difficult when working with mixed categories.

In almost all editions of CORINE, mixed categories are involved in most of the change mapped by CHA and CLC layers. In CHA layers and the first two CLC layers $(90,00)$ most of this dynamism is driven by the changes among natural vegetated areas and all changes from and to transitional woodland/shrub. Moors and heathland, a category whose definition is similarly imprecise, is also one of the main drivers of the mapped LUC change in all CORINE editions. In the two last editions of CORINE, CLC layers show a lot of changes where heterogeneous agricultural areas categories (complex cultivation patterns and land principally occupied by agriculture) are involved, which can be attributed to technical changes because of the different method of production of CORINE (see previous section).

Maucha et al. (2011) analyzed the inconsistencies between CHA00 and CHA06 layers for all Europe. Mixed categories and, specifically, transitional woodland/shrub and complex cultivation patterns, were found to be behind most of the checked inconsistencies. Although this may be caused by the important dynamism of the areas mapped under these categories, it may there be a correlation between the use of mixed categories and the higher uncertainty of the mapping process. In fact, part of the inconsistencies detected by Maucha et al. (2011) were attributed to the subjectivity when mapping and differentiating these categories from other ones. The results of our study 
This manuscript has been submitted for publication in "International Journal of Remote Sensing". Subsequent versions of this manuscript, after acceptance and review by the journal, may have slightly different content. If accepted, the final version of this manuscript will be available via the `Peer-reviewed Publication DOI'

and, specifically, the categories involved in the technical changes detected in the 2012 and 2018 editions of CORINE, point out in this direction.

The better characterization of the areas assigned to mixed categories could be a solution to this problem. In this regard, a survey carried out by the EEA among the CORINE participating countries revealed an interest of several countries to subdivide mixed categories such as complex cultivation patterns, land principally occupied by agriculture and transitional woodland/shrub (European Environment Agency, 2021). The subdivision of the last category was the one that attracted more interest among the countries that were consulted. The detailed information provided by national LUC datasets, like SIOSE, could be useful when carrying out this task. Nonetheless, the generation of the new CLC+ may already give an answer to this problem. It will provide LUC information at finer spatial and thematic scales that the current CORINE (Kleeschulte et al., 2017).

On the other hand, when obtaining CORINE through semi-automated methods, like in the 2012 and 2018 editions, more attention should be paid to the uncertainty attached to the mapping of mixed categories. In this regard, these categories refer to abstract associations of elements that usually operate at specific scales. For CORINE, as pointed out by García-Álvarez and Camacho Olmedo (2017), mixed categories easy to delineate and understand at that scale, can refer to a different landscape conceptualization at finer scales like SIOSE. It is the so-called individualistic fallacy problem (Cao and SiuNgan Lam, 1997). Now, when CORINE is generalized from a very high detailed LUC database (SIOSE Alta Resolución), the problem can be bigger and the obtained result more uncertain. 
This manuscript has been submitted for publication in "International Journal of Remote Sensing". Subsequent versions of this manuscript, after acceptance and review by the journal, may have slightly different content. If accepted, the final version of this manuscript will be available via the 'Peer-reviewed Publication DOI'

\section{Conclusions}

CORINE Land Cover is one of the most important Land Use Cover datasets in Europe, widely used across sectors and disciplines. Its long time series, providing LUC data since 1990 until nowadays, with an updating period of 6 years, makes this dataset very useful for different users and researchers interested in temporal analyses. However, the use of the CORINE's time series come with important limitations and uncertainties that not all users know.

CORINE status layers (CLC) include a lot of technical changes that hamper their comparison to analyse LUC change through time. Instead, users must work with the CORINE layers of changes (CHA). However, these also present small inconsistencies. Although not very relevant, they could be easily addressed to reduce the uncertainty of CHA layers to the minimum. For those users that require status layers instead of layers of changes, the CORINE production team has also developed a specific product in raster format at 100m that provides a consistent time series of LUC data: the CLC accounting layers. Notwithstanding, this product is still being improved and, although less uncertain than the standard CLC layers, users should be aware about their limitations.

In Spain, the change of production of CORINE since 2012 has meant a lot of changes in the database that require further analysis. It is required a specific study about the impact of the change of methodology in the mapping of changes. In addition, information should be provided about the last update of CORINE in Spain to explain the technical changes that have been found.

We have identified a general lack of transparency and detailed information on the uncertainties and changes of method of production of CORINE in Spain. Although 
This manuscript has been submitted for publication in "International Journal of Remote Sensing". Subsequent versions of this manuscript, after acceptance and review by the journal, may have slightly different content. If accepted, the final version of this manuscript will be available via the 'Peer-reviewed Publication DOI'

the CORINE Land Cover programme has included many questions not addressed until the moment in the last user manual, the information that this document provides is generic and not enough to understand the uncertainties and limitations of the CORINE datasets for each of the mapped countries. In this regard, we demand more information from the national organisms in charge of producing CORINE and, specifically for Spain, from the Instituto Geográfico Nacional.

\section{Data availability statement}

The data that support the findings of this study are available in the Copernicus Land Monitoring Service website at https://land.copernicus.eu/pan-european/corine-landcover, reference number

\section{References}

Aune-Lundberg, L. and Strand, G.-H. (2010) Corine Land Cover Classes. Examination of the content of CLC classes in Norway. Available at: http://www.skogoglandskap.no/en/pubs/corine_land_cover_classes_examination _of_the_content_of_clc_classes_in_norway/publication_view.

Aune-Lundberg, L. and Strand, G.-H. (2021) 'The content and accuracy of the CORINE Land Cover dataset for Norway', International Journal of Applied Earth Observation and Geoinformation, 96, p. 102266. doi: 10.1016/j.jag.2020.102266.

Bach, M. et al. (2006) 'Accuracy and congruency of three different digital land-use maps', Landscape and Urban Planning, 78(4), pp. 289-299. doi: 10.1016/j.landurbplan.2005.09.004. 
This manuscript has been submitted for publication in "International Journal of Remote Sensing". Subsequent versions of this manuscript, after acceptance and review by the journal, may have slightly different content. If accepted, the final version of this manuscript will be available via the 'Peer-reviewed Publication DOI'

Barreira González, P., González Cascón, V. and Bosque Sendra, J. (2012) ‘Detección de errores temáticos en el CORINE Land Cover a través del estudio de cambios: Comunidad de Madrid (2000-2006)', Estudios Geograficos, 73(272), pp. 7-34. doi: 10.3989/estgeogr.201201.

Bontemps, S. et al. (2012) 'Revisiting land cover observation to address the needs of the climate modeling community', Biogeosciences, 9(6), pp. 2145-2157. doi: 10.5194/bg-9-2145-2012.

Burkhard, B. et al. (2012) 'Mapping ecosystem service supply, demand and budgets', Ecological Indicators, 21, pp. 17-29. doi: 10.1016/j.ecolind.2011.06.019.

Büttner, G. (2014) 'CORINE Land Cover and Land Cover Change Products', in Manakos, I. and Braun, M. (eds) Land Use and Land Cover Mapping in Europe: Practices \& Trends. Dordrecht, Heidelberg, New York, London: Springer, pp. 55-74. doi: 10.1007/978-94-007-7969-3_5.

Büttner, G. and Kosztra, B. (2011) Manual of CORINE Land Cover changes. Available at: https://land.copernicus.eu/user-corner/technicallibrary/manual_of_changes_final_draft.pdf.

Caetano, M., Mata, F. and Freire, S. (2006) 'Accuracy assessment of the Portuguese CORINE Land Cover map', in Global Developments in Environmental Earth Observation from Space. Proceedings of the 25th EARSeL Symposium. Porto: Millpress, pp. 459-627.

Cao, C. and Siu-Ngan Lam, N. (1997) 'Understanding the Scale and Resolution Effects in Remote Sensing and GIS', in Quattrochi, D. A. and Goodchild, M. F. (eds) Scale in Remote Sensing and GIS. Boca Raton: CRC press, pp. 57-72.

Catalá Mateo, R., Bosque Sendra, J. and Plata Rochas, W. (2008) 'Análisis de posibles errores en la base de datos Corine Land Cover (1990-2000) en la Comunidad de Madrid', Estudios geográficos, 69, pp. 81-104.

Cortizo Álvarez, T., Fernández García, F. and Maceda Rubio, A. (1990) 'Asturias', in Bosque Maurel, J. and Vilá Valentín, J. (eds) Geografía de España 4. Galicia, Asturias y Cantabria. Barcelona: Planeta, pp. 289-460.

Delgado Hernández, J. et al. (2017) 'Sistema de información sobre Ocupación del Suelo en España (SIOSE) de Alta Resolución, metodología de integración automática', in Ruiz, L. A., Estornell, J., and Erena, M. (eds) Nuevas plataformas y sensores 
This manuscript has been submitted for publication in "International Journal of Remote Sensing". Subsequent versions of this manuscript, after acceptance and review by the journal, may have slightly different content. If accepted, the final version of this manuscript will be available via the 'Peer-reviewed Publication DOI'

de teledetección. XVII Congreso de la Asociación Española de Teledetección. Murcia, pp. 307-310.

Diaz-Pacheco, J. and Gutiérrez, J. (2013) 'Exploring the limitations of CORINE Land Cover for monitoring urban land-use dynamics in metropolitan areas', Journal of Land Use Science, (February 2013), pp. 1-17. doi: 10.1080/1747423X.2012.761736.

Equipo Técnico Nacional SIOSE (2020) Sistema de Información de Ocupación del Suelo en España de Alta Resolución (SIOSE AR). Available at: https://www.siose.es/SIOSEtheme-

theme/documentos/pdf/Documento_Tecnico_SIOSE_AR_v1.pdf.

European Environment Agency (2021) Copernicus Land Monitoring Service. CORINE Land Cover. User Manual. Available at: https://land.copernicus.eu/paneuropean/corine-land-

cover/clc2018?tab=metadata\%0Ahttps://land.copernicus.eu/paneuropean/corine-land-cover/clc2018\%0Ahttps://land.copernicus.eu/paneuropean/corine-land-cover/clc2018\%0Ahttps://land.copernicus.eu/pan-europea.

Falt'an, V. et al. (2020) 'Comparison of CORINE land cover data with national statistics and the possibility to record this data on a local scale-case studies from Slovakia', Remote Sensing, 12(15). doi: 10.3390/RS12152484.

Felicísimo, A. M. and Sánchez Gago, L. M. (2002) 'Thematic and spatial accuracy: a comparison of the Corine Land Cover with the Forestry Map of Spain', 5th AGILE Conference on Geographic Information Science, Palma (Balearic Islands, Spain) April 25th-27th 2002, pp. 1-10.

Fernández Nogueira, D. (2021) Cambios recientes en los usos de suelo en la Península Ibérica (Portugal-España). doi: http://hdl.handle.net/10347/26038.

Fonte, C. C. et al. (2020) 'Assessing the accuracy of land use land cover (LULC) maps using class proportions in the reference data', in ISPRS Annals of the Photogrammetry, Remote Sensing and Spatial Information Sciences, pp. 669674. doi: 10.5194/isprs-Annals-V-3-2020-669-2020.

Gallego, J. (2001) 'Fine scale profile of CORINE Land Cover classes with LUCAS data', in Building agri-environmental indicators: focussing on the European area frame survey LUCAS, pp. 121-136. 
This manuscript has been submitted for publication in "International Journal of Remote Sensing". Subsequent versions of this manuscript, after acceptance and review by the journal, may have slightly different content. If accepted, the final version of this manuscript will be available via the 'Peer-reviewed Publication DOI'

García-Álvarez, D. et al. (eds) (2022) Land Use Cover Datasets and Validation Tools: Validation Practices with QGIS. Springer.

García-Álvarez, D. and Camacho Olmedo, M. T. (2017) 'Changes in the methodology used in the production of the Spanish CORINE: Uncertainty analysis of the new maps', International Journal of Applied Earth Observation and Geoinformation, 63, pp. 55-67. doi: 10.1016/j.jag.2017.07.001.

García-Álvarez, D. and Camacho Olmedo, M. T. (2021) 'Potential uncertainties of CORINE Land Cover (CLC) for Land Use Cover Change (LUCC) analyses at supranational scales', in International Conference of EUROGEO 2021 'Sustainable Development Goals for all'.

García-Álvarez, D. and Florina Nanu, S. (2022) 'Land Use Cover Datasets: a review', in García-Álvarez, D. et al. (eds) Land Use Cover Datasets and Validation Tools: Validation Practices with QGIS. Springer.

Gemitzi, A. et al. (2021) 'Land cover and vegetation carbon stock changes in Greece: A 29-year assessment based on CORINE and Landsat land cover data', Science of the Total Environment, 786. doi: 10.1016/j.scitotenv.2021.147408.

Giri, C. P. (2016) Remote sensing of land use and land cover: Principles and applications, Remote Sensing of Land Use and Land Cover: Principles and Applications.

Goerlich, F. J. and Cantarino, I. (2013) 'A population density grid for Spain', International Journal of Geographical Information Science, 27(12), pp. 22472263. doi: 10.1080/13658816.2013.799283.

Green, G. M., Schweik, C. M. and Randolph, J. C. (2005) 'Linking Disciplines across Space and Time: Useful Concepts and Approaches for Land-Cover Change Studies', in Moran, E. F. and Ostrom, E. (eds) Seeing the Forest and the Trees: Human-environment Interactions in Forest Ecosystems. MIT Press. Available at: https://www.ebsco.com/terms-of-use.

Hazeu, G. et al. (2016) 'Detailed CLC Data: Member States with CLC Level 4/Level 5 and (Semi-) Automated Solutions', in Feranec, J. et al. (eds) European Landscape Dynamics. CORINE Land Cover Data. Boca Raton: CRC Press, pp. 275-304. doi: 10.1201/9781315372860-27. 
This manuscript has been submitted for publication in "International Journal of Remote Sensing". Subsequent versions of this manuscript, after acceptance and review by the journal, may have slightly different content. If accepted, the final version of this manuscript will be available via the 'Peer-reviewed Publication DOI'

Hewitt, R. and Escobar, F. (2011) 'The territorial dynamics of fast-growing regions: Unsustainable land use change and future policy challenges in Madrid, Spain', Applied Geography, 31(2), pp. 650-667. doi: 10.1016/j.apgeog.2010.11.002.

Kleeschulte, S. et al. (2017) Technical specifications for implementation of a new landmonitoring concept based on EAGLE. D3: Draft design concept and CLCBackbone, CLC-Core technical specifications, including requirements review. Version 3.0.

Kucsicsa, G. et al. (2019) 'Future land use/cover changes in Romania: regional simulations based on CLUE-S model and CORINE land cover database', Landscape and Ecological Engineering, 15(1), pp. 75-90. doi: 10.1007/s11355018-0362-1.

Mañas, M. de S. O., Soria, C. and Ramírez, A. (2003) 'Validation of the CORINE land cover database in a pilot zone under semi-arid conditions in La Mancha (Spain)', Cybergeo. doi: 10.4000/cybergeo.4233.

Martínez-Fernández, J. et al. (2019) 'Methodological variations in the production of CORINE land cover and consequences for long-term land cover change studies. The case of Spain.', International Journal of Remote Sensing, 40(23), pp. 89148932. doi: 10.1080/01431161.2019.1624864.

Maucha, G., Büttner, G. and Pataki, R. (2011) Development of methodology to eliminate contradictions between CLC-change 1990-2000 and CLC-Change 2000-2006.

Nedd, R. et al. (2021) 'A synthesis of land use/land cover studies: Definitions, classification systems, meta-studies, challenges and knowledge gaps on a global landscape', Land, pp. 1-30. doi: 10.3390/land10090994.

Neumann, K. et al. (2007) 'Comparative assessment of CORINE2000 and GLC2000: Spatial analysis of land cover data for Europe', International Journal of Applied Earth Observation and Geoinformation, 9(4), pp. 425-437. doi: 10.1016/j.jag.2007.02.004.

Ovejero-Campos, A. et al. (2019) 'Methodological limitations of CLC to assess land cover changes in coastal environments', Journal of Coastal Conservation, 23(3), pp. 657-673. doi: 10.1007/s11852-019-00696-w.

Perez-Hoyos, A., Garcia-Haro, F. J. and Valcárcel, N. (2014) 'Incorporating subdominant classes in the accuracy assessment of large-area land cover products: 
This manuscript has been submitted for publication in "International Journal of Remote Sensing". Subsequent versions of this manuscript, after acceptance and review by the journal, may have slightly different content. If accepted, the final version of this manuscript will be available via the 'Peer-reviewed Publication DOI'

Application to GlobCover, MODISLC, GLC2000 and CORINE in Spain', IEEE Journal of Selected Topics in Applied Earth Observations and Remote Sensing, 7(1), pp. 187-205. doi: 10.1109/JSTARS.2013.2258659.

Probeck, M. et al. (2021) 'CLC+ Backbone: Set the Scene in Copernicus for the Coming Decade', in 2021 IEEE International Geoscience and Remote Sensing Symposium IGARSS. Brussels: IEEE, pp. 2076-2079. doi: 10.1109/igarss47720.2021.9553252.

Rodríguez Gutiérrez, F. and Menéndez Fernández, R. (2005) Geografía de Asturias: la reestructuración territorial de una región de tradición industrial. Barcelona: Ariel.

Rodríguez Gutiérrez, F., Menéndez Fernández, R. and Blanco Fernández, J. (2009) El área metropolitana de Asturias. Ciudad Astur: el nacimiento de una estrella urbana en Europa. Oviedo: Trea. Available at: http://dialnet.unirioja.es/servlet/libro?codigo=363783 (Accessed: 7 July 2015).

Rusu, A. et al. (2020) 'Structural changes in the romanian economy reflected through corine land cover datasets', Remote Sensing, 12(8). doi: 10.3390/RS12081323.

Śleszyński, P., Gibas, P. and Sudra, P. (2020) 'The Problem of Mismatch between the CORINE Land Cover Data Classification and the Development of Settlement in Poland', Remote Sensing, 12(14), p. 2253. doi: 10.3390/rs12142253.

Teixeira, Z., Marques, J. C. and Pontius Jr., R. G. (2016) 'Evidence for deviations from uniform changes in a Portuguese watershed illustrated by CORINE maps: An Intensity Analysis approach', Ecological Indicators, 66, pp. 382-390. doi: 10.1016/j.ecolind.2016.01.018.

Torma, M. and Harma, P. (2004) 'Accuracy of CORINE land cover classification in Northern Finland', in 2004 IEEE International Geoscience and Remote Sensing Symposium Proceedings. IEEE, pp. 227-230. doi: 10.1109/IGARSS.2004.1369002.

Valcárcel Sanz, N. and Castaño Fernández, S. (2012) Cartografía de ocupación del suelo en España. Proyecto SIOSE. Edited by N. Valcárcel Sanz and S. Castaño Fernández. Madrid: CNIG. doi: http://dx.medra.org/10.7419/162-6882. 
This manuscript has been submitted for publication in "International Journal of Remote Sensing". Subsequent versions of this manuscript, after acceptance and review by the journal, may have slightly different content. If accepted, the final version of this manuscript will be available via the 'Peer-reviewed Publication DOI'

Villa, G. et al. (2008) 'Land Cover Classifications: An Obsolete Paradigm', in Chen, J., Jiang, J., and Nayak, S. (eds) The International Archives of the Photogrammetry, Remote Sensing and Spatial Information Sciences. Beijing: ISPRS, pp. 609-614. 